\title{
Tarihî Bakımdan Cürçence-Mançuca İlişkisi ve Cürçencedeki Bazı Türkçe Kökenli Kelimeler Üzerine
}

\author{
Historical Relation of Jurchen-Manchu and on Some Words of Turkic Origin in \\ Jurchen
}

\author{
Uluhan Özalan \\ Dr. Helsinki Üniversitesi \\ Edebiyat Fakültesi, Altayistik Çalışmaları Bölümü, Helsinki / Finlandiya \\ e-posta uluhan.ozalan@helsinki.fi \\ orcid 0000-0002-9865-6010 \\ doi $\quad 10.54316 /$ dilarastirmalari.1014250
}

\section{Atıf}

Citation

Özalan, Uluhan (2021). Tarihî Bakımdan CürçenceMançuca İlişkisi ve Cürçencedeki Bazı Türkçe Kökenli Kelimeler Üzerine. Dil Araştır-maları, 29: 67-77.

Başvuru
Submitted
25.10 .2021
Revizyon
Revised
09.11 .2021
Kabul
Accepted
10.11.2021
Çevrimiçi Yayın
Published Online
30.11.2021

Başvuru

Submitted

Revizyon

Revised

09.11 .2021

Kabul

Accepted

30.11.2021
Öz

Liao devletine (916-1125) son vererek Çin'in kuzeyinde Cin hanedanını (1115-1234) kuran Tunguz topluluğunun dili olan Cürçence bugünkü verilere göre yazıya geçirilen ilk Tunguz dilidir. Cin ve Ming (13681644) dönemlerinden kalan metinlerle takip edilebilmektedir. Tunguz dil ailesi içinde Cürçence, Mançuca ve Sibecenin tarihsel olarak birbirinin devamı olduğu genellikle kabul edilir. Çing döneminde (1644-1911) Cürçen toplulukları kendilerine Mançu demeye başlamıştır. Mançucayla Cürçence arasında sesbilgisi ve şekilbilgisi bakımından bazı küçük farklar olmakla birlikte iki dilin tarihî olarak birbirinin devamı olamayacağı da bazı araştırmacılar tarafindan belirtilir. $\mathrm{Bu}$ yazıda, Cürçenlerin tarihinden bahsedilerek Cürçencenin kaynaklarına değinilmiştir. Ayrıca Cin ve Ming dönemi Cürçencesi ile Mançuca arasındaki dilbilgisi bakımından benzerlikler ve farklar gösterilmiştir. Bundan başka, Cürçenceye Moğolca aracılığıyla geçen Türkçe kelimeler tespit edilerek bunların diğer Tunguz dillerindeki yayılımı gösterilmiş ve Türk-Tunguz dil ilişkileri bağlamında ele alınmıştır.

Anahtar Kelimeler: Cürçence, Mançuca,Tunguz dilleri, Türkçe, dil ilişkileri

\section{ABSTRACT}

Jurchen is the language of the Tungusic people who supplanted the Liao State (916-1125) and formed the Jin Dynasty (1115-1234) in northern China. On the basis of the available data, Jurchen is known to be the first Tungusic language ever recorded in writing. It can be traced through written materials during Jin and Ming (1368-1644) periods. Besides, Jurchen, Manchu and Sibe are regarded to be the historical continuation of the same language. As an ethnonym Jurchen was replaced by Manchu in the Qing period (1644-1911). Since there are some slight phonological 
and morphological differences between Jurchen and Manchu, some researchers state that Manchu is not a direct descendant of Jurchen. In the present paper, the sources of the Jurchen language are introduced with reference to Jurchen history. As for the linguistic history of Jurchen, the linguistic divergences among Jin and Ming Jurchen, and Manchu are presented. Additionally, the words with Turkic origin borrowed through Mongolic mediation in Jurchen are determined and their spread in the Tungusic language family is discussed within the framework of TurkicTungusic contact.

Keywords: Jurchen, Manchu, Tungusic, Turkic, language contacts

\section{Giriş}

Cürçenler Kitan hâkimiyetine son vererek Çin'in kuzeyinde 1115-1234 yılları arasında hüküm süren Cin Hanedanını kuran Tunguz topluluğudur. Mançuların atası olarak kabul edilen Cürçenlerin dili olan Cürçence bugün eldeki verilere göre yazıya geçirilen ilk Tunguz dilidir. Bilindiği gibi, bazı araştırmacılar tarafından aynı dilin art zamanlı kolları olarak değerlendirilen Cürçence, Mançuca ve Sibece Tunguz dilleri arasında, grubun diğer üyelerinden özellikle ses bilgisi bakımından önemli bazı farklılıklar gösterir. Şekil bilgisi bakımından da Çince ve Moğolcanın etkisiyle diğer Tunguz dillerine göre daha "basitleşmiş" bir yapı dikkat çeker. Bu yüzden Tunguz dilleri içinde bu üç dil Cürçen grubu diller (Jurchenic) olarak kabul edilir (Janhunen 2015: 576). Cürçen-Mançu kolunun proto-Tunguzcadan yaklaşık olarak 2000-2500 y1l önce ayrıldığı tahmin edilmektedir (Pevnov 1997: 260-261). Moğolca, para-Moğolca ${ }^{1}$, Çince ve Korecenin etkisinde kalması nedeniyle Cürçence ve Mançuca diğer Tunguz

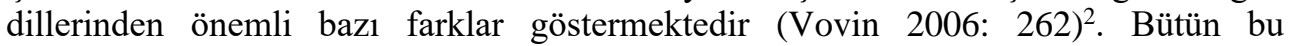
farklılardan dolayı Cürçence, Mançuca ve Sibece Tunguz dilleri sınıflandırmalarında ayrı bir konumda değerlendirilir. Bununla birlikte, erken dönem sinıflandırmalarında bu ayrımının yapılmadığı da dikkat çeker. Yapılan sınıflandırmalar daha çok eş zamanlı dilleri kapsadığı için bazı sınıflandırma denemelerinde Cürçenceye yer verilmediği görülür. Ancak, Cürçence ve Mançucanın sesbilgisi ve şekilbilgisi bakımından oldukça yakın oldukları dikkate alınınca, art zamanlı olarak Cürçencenin Mançuca kolunda yer alması beklenir. Nitekim İkegami ve Janhunen aşağıda verilen sınıflandırmalarına Cürçenceyi de dâhil etmişlerdir. Tunguz dillerine dair bir sınıflandırma teklif eden araştırmacılardan bazıları ve yaptıkları sınıflandırmalar şu şekildedir;

\footnotetext{
1 Cürçence ve Mançuca diğer Tunguz dillerinde görülmeyen bazı Moğolca unsurlara sahiptir. Özellikle Moğol imparatorluğundan önceki döneme ait Moğolca alıntıların kaynağı para-Moğolca bir dil olan Kitan dilidir (Janhunen 2015: 579). Ayrıca, bu dilin dönemin bölgedeki en güçlü devleti olan Liao devletinin (907-1125) dili olduğu göz önünde bulundurulunca Cürçencedeki para-Moğolca unsurların varlığı anlaşılabilir bir durumdur. Eğitimli Cürçenlerin kendi dillerinden başka Kitan dilini de bildiği ifade edilir (Janhunen 2015: 577).

${ }^{2}$ Bilindiği gibi, iyelik ve kişi ekleri diğer Tunguz dillerinde korunurken Mançuca ekleşme dizisinde bu unsurlar kullanımdan düşmüştür. Alonso de la Fuente (2011) Mançucanın morfolojik yapısının diğer Tunguz dillerine göre daha basit olmasını, Mançucada arkaik bazı özelliklerin korunmasıyla açıklar.
} 
Cincius (1949: 12-13) Tunguz dillerini Kuzey ve Güney Tunguz dilleri olarak ayırdıktan sonra Kuzey dillerini "Evenki, Even, Negidal, Solon” Güney dillerini ise "Mançu, Nanay, Udege, Ulçi, Orok ve Oroç" dilleri olarak verir. Benzin (1956: 9-10) de hemen hemen aynı sinıflandırmayı benimser fakat siniflandırmasina bu dillerin ağızlarını da dâhil eder.

Menges (1968: 28) bu dil ailesini üç grup altında ele almıştır. Kuzey grubunda Evenki ve Even dilleri, Güney grubunda Nanay, Orok, Ulçi, Mançu dilleri vardır. Geçiş (transitional) grubu olarak adlandırdığı üçüncü grupta ise Solon, Negidal, Oroç ve Udege dillerini verir.

İkegami (1974: 271) Tunguz dillerini Evenki, Udege, Nanay ve Mançu grubu olmak üzere dört başlikta değerlendirir. Evenki grubunda Evence, Arman Evencesi, Sibirya Evenkicesi, Negidalca, Oroçence, Hamnigan Evenkicesi, Mançurya Soloncası ve Ongkor Soloncası bulunur. Udege grubunda Udege ve Oroç dilleri, Nanay grubunda Nanay, Kili, Kilen, Ulça, Orok dilleri vardır. Mançu grubuna ise Mançuca, Sibece ve bunların tarihî kolu olan Cürçence girer.

Doerfer (1978: 5) ise sınıflandırmasında Mançucayı ayrı bir grupta değerlendirir. Tunguz dillerini Güney, Merkez ve Kuzey grubu olarak ayıran Doerfer, Güney grubunda Mançucaya, Merkez grubunda Udege ve Nanay dillerine, Kuzey grubunda da Evenki ve Even dillerine yer verir.

Janhunen (2012: 6) Tunguz dillerini önce Kuzey ve Güney grubu olarak ayırır. Kuzey grubunu kendi içinde 1. Evenki-Even, 2. Udege-Oroç, Güney grubunu da 1. Nanai-Ulça-Orok ve 2. Cürçen-Mançu alt grupları olarak verir.

Mançu adının bir etnonim olarak kullanımı oldukça yenidir. Ancak Cürçen adı Cin hanedanı döneminde (1115-1234) de bir etnonim olarak kullanılmaktaydı (Janhunen 2004: 67). Bilindiği üzere Nurhaci’nin oğlu Hong Taici (1529-1643) yönetiminde siyasi ve askeri bakımdan güçlenmeye devam eden bu Cürçen topluluklarına 1635 yılından itibaren Mançu denmeye başlanmıştır. Çing hanedanın kurucu imparatoru olan Hong Taici'nin yönettiği topluluğun adını Mançu olarak değiştirmesinin bazı sebepleri vardır. Cürçen adının Ming hanedanın tebaası oldukları dönemleri çağrıştırması ve olumsuz çağrışımı ortadan kaldırma isteği bu sebeplerden biridir. Başka bir sebep ise, hâkimiyet altına aldıkları Cürçen olmayan tebaanın sayısının gün geçtikçe artması dolayısıyla Cürçen adının bütün bu toplulukları temsil etmemesidir. $\mathrm{Bu}$ bakımdan, bütün etnik grupları kapsayacak yeni bir isime ihtiyaç duyulmuştu (Huang 1990: 280). Batı literatüründe Jurchen olarak geçen bu etnonomin Moğolca kökenli olduğu ifade edilir; (*)jürcin (*)jörcin çokluk biçimiyle $(*) j u ̈ r c i-d \sim(*) j o ̈ r c i-$ $d$. Kelime Moğolların Gizli Tarihinde de jürced olarak geçmektedir. Kelimenin batı dillerine Moğolcadan alıntılanmış olmasının sebebi ortada bulunan (*)r sesidir, çünkü kelimenin Cürçence ve Mançuca biçimlerinde bu ses yoktur. Mançucada juşen olarak geçen kelime Çing döneminde köle anlamında da kullanılmıştır. Mançuca /ş/ sesinin Moğolcada /c/'ye denk geldiğini gösteren örnekler de vardır; Man. şanggiyan Mo. çagaxan "beyaz". Mançuca juşen biçiminin daha eski olan ve doğrudan veya dolaylı olarak Çince (女真) ruzen veya nüzhen'e kaynaklık eden *jucen kelimesinden geldiği düşünülebilir. Mançuca /u/ sesinin proto-Tunguzca /ö/ veya /ü/ sesinden geldiği dikkate alınınca kelimenin aslî şeklinin *jöcen ya da *jücen olması beklenir. Kelime 
bugün bazı Moğol dillerinde /ö/'lü biçimiyle kaydedildiği ve ö>ü değişimi ters istikametteki değişime göre daha yaygın olduğu için kelimenin Moğolcadaki biçiminin *jörcin olması gerekir, bunun da ses denkliği bakımından Tunguzca karşılığı *jöcen olur. Dolayısıyla, Moğolca kelimenin Tunguzcadan alıntılandığına dair pek kuşku yoktur. Cürçence ve Mançucada hece sonundaki /r/ seslerinin düşme eğilimi vardır. Mançuca juwe "iki” < proto-Tunguzca *jöör. Bu sebeple Mançuca kelime, Moğolcadaki biçime de kaynaklık eden daha eski bir *jörcen biçimine götürülebilir (Janhunen 2004: 67-68).

Kane, Kitan diliyle yazılmış olan bir yazıtta geçen «n.i.gu g.úr:en〉 ifadesindeki n.i.gu kelimesinin Kitan dilinde Cürçen anlamına geldiğini belirtir. Pelliot ise Çince nüzhen kelimesinin Liao döneminden önce Çincede görülmediğini ve Çince bu kelimenin Kitan dilindeki kelimeden geldiğini söyler. Cürçenler kendi devletlerine alçun "altın" diyorlard1. Çince jin 金 ve Kitan dilindeki n.i.gu kelimeleri de altın anlamındadır. *nigü olarak okunabilecek bu kelime Kitan dilinde hem altın hem de Cürçen anlamlarına sahiptir. Dolayısıyla kelimenin Çincesi olan nüzhen Kitan dilinde altın ve Cürçen anlamlarına gelen *nigü kelimesiyle ilgilidir (Kane 2009: 165).

Tang hanedanının (618-907) dağılmasından sonra Çin'in kuzeyini hâkimiyetleri altına alan Kitanlar bu bölgede Liao devletini (916-1125) kurdular. Liao devletine son veren Cürçenler ise 1115 yılında Cin Hanedanını kurdular. Ancak daha sonra Moğollar Cin hanedanını ortadan kaldırarak yerine Yuan hanedanını (1271-1368) kurdu. Bu dönemde Cürçenler Moğollara bağlı olarak yaşadılar (Janhunen 1996: 131-134). Ayrıca Yuan hanedanı döneminde Cürçenlerin Mançurya'ya çekildiği de bilinmektedir (Rachewilts ve Rybatzki 2010: 262). Ming hanedanı (1368-1644) döneminde de Cürçenler bağlı oldukları hanedana vergi ödeyen bir halk olarak karşımıza çıkar.16. yüzyıl ortalarından itibaren siyasi bakımdan tekrar güçlenmeye başlayan Cürçenler, 17. yüzyılda Mançu adıyla yeniden tarih sahnesine çıktılar ve Çin'i yöneten son hanedan olan Çing hanedanını (1644-1911) kurdular (Pevnov 1997: 260). Cürçenceye ait dil yadigârları Cin döneminden itibaren takip edilebilmektedir. Çing döneminde ise Cürçence yerini artık Mançucaya bırakmıştır.

\section{Cürçencenin Kaynakları ve Dilbilgisi Özellikleri}

Cürçence yukarıda da ifade edildiği gibi bugünkü bilgilere göre yazıyla kaydedilen ilk Tunguz dilidir. Cürçenlerin dili ve bu dili yazmak için kullandıkları yazı sistemleri Ming dönemine (1368-1644) kadar varlığını sürdürmüştür.

Cürçence iki farklı Sinitik yazı sistemi ile yazılmıştır. "Büyük yazı" olarak adlandırılan alfabe 1119 ' da, "küçük yazı” denen alfabe ise 1138 yılında geliştirilmiştir. Eldeki Cürçence eserlerin önemli bir bölümü "büyük yazı" ile kaydedilmiştir. Her iki yazı da Kitanların büyük ve küçük yazıları ile bir şekilde ilgilidir. Aslında Cürçenlerin eğitimli olanları Kitan dili ve Çince biliyorlardı, bu bakımdan kendi dillerini yazıya geçirmek için Kitan ve Çin karakterlerinden etkilenmeleri beklenmeyen bir durum olarak değerlendirilemez. Cürçenlerin Cin hanedanının ilk dönemlerinde kendilerine ait bir yazıları yoktur. $\mathrm{Bu}$ nedenle diğer devletlerle ilişkilerinde Kitan yazısını kullandilar. Daha sonra İmparator Taizu, Xiyin adlı bir saray memurunu Cürçence 
yazmak için kullanılacak bir yazı geliştirmesi için görevlendirdi. Xiyin 1119 yılında, Kitan ve Çin yazılarının bazı özelliklerini birleştirerek Cürçence "büyük yazı" sistemini geliştirdi. Küçük yazı olarak adlandırılan ikinci yazı sistemi ise İmparator Xizong döneminde geliştirilmiş ve önceki yazı sistemi ile birlikte Cürçenceyi kaydetmek için kullanılmıştır (Kane 1989:10). Birçok bakımdan Cürçencenin devamı sayılan Mançuca ise Moğollardan alınan alfabe ile yazıya geçirilmiştir.

Ortaçağda Çin'in kuzey bölgesinde Kitanlar Liao, Cürçenler Cin ve Tangutlar Xia devletlerini kurmuşlardır. Üç siyasi yapı da merkez Çin'den bağımsız olduklarını göstermek için kendi yazı sistemlerini geliştirmiştir. Kitanlar 920 yılında büyük yazıyı, 925 yılında da küçük yazıyı geliştirmiş, Tangutlar da kendi yazı sistemlerini 1036 yılında kullanmaya başlamışlardır Cürçenler, Kitanlar gibi büyük ve küçük olarak adlandırılan iki yazı sistemi geliştirmişlerdi. Özellikle Cürçence büyük yazı Kitan dilinin kaydedildiği büyük yazıyla oldukça benzer özelliklere sahiptir (Janhunen 1994: 107-110). Bu yazıların çözülmesinde önemli mesafeler alınmış olmakla birlikte hâlâ problemli birçok mesele bir sonuca bağlanamamıştır.

Cin döneminden kalan dil malzemeleri üç kaynaktan oluşur; Bir kısmı Çince iki dilli olan Cürçence on kadar yazıt, iki el yazması belge, Cürçence kelimelerin Çince karakterlerle yazıya geçirildiği bir sözlük. Ming dönemi Cürçencesine ait eserler ise 1413 yılında dikilen bir anıt ve Hau-i i-yü başlıklı sözlügün Cürçence bölümüdür. Özellikle bu son kaynak Cürçencenin çözülmesi ve anlaşılması için son derece önemlidir. Bu sözlüğün Cürçen yazısı ile kaydedilmiş bölümü ve sadece Çince transkripsiyonu içeren bölüm Ming döneminin mütercim ve tercüman odaları tarafından derlenmiştir (Kiyose 2000: 177). Bunlardan tercüman odasının derlediği kelimeler üzerinde Grube (1896) ve Kiyose (1977) tarafindan yapılan iki önemli çalışma vardır. Mütercim odasının derlediği kelimeler ise Kane (1989) tarafından yayımlanmıştır.

Cin dönemi Çürçencesi ile Ming dönemi Cürçencesi arasında dilbilgisi bakımından bazı farklar vardır;

Proto-Tunguzca */p-/ sesi Cin dönemi Cürçencesinde korunmuştur, ancak Ming dönemi Cürçencesinde aynı ses */f-/ olmuştur; Proto-Tunguzca pokaran "küçük" > Cin

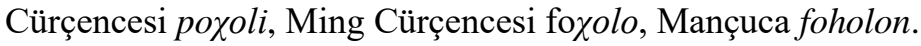

Aynı şekilde $\mathrm{y}$ - sesi de Cin döneminde korunmuş, Ming döneminde g-'ye dönüşmüştür;

Cin Cürçencesi yun "değerli taş" > Ming Cürçencesi gun

Proto-Tunguzcada /a/,/o/,/u/, /1/, /e//ö/, /ü/, /i// olmak üzere sekiz ünlü tasarlanmaktadır. Cin dönemi Cürçencesinde /1/ ve /i/ seslerinin birleştiğini görülür. Dolayısıyla bu dönemin dilinde /i/ sesi ünlü uyumu bakımdan tarafsız hâle gelmiştir. Ming dönemi Cürçencesinde /a/, /o/, /e/, /u/ ve /i/ ünlüleri vardır, bunlardan /u/ ve /i/ ünlü uyumu bakımından tarafsızdır. Cin dönemi eklerin alt şekilleri (allomorph) bakımından Ming dönemine göre daha zengindir;

Yönelme-bulunma hâli; -do/-dö>-do

Edilgen-ettirgen çatı eki; -bu,-bü>-bu

Belirtme hâli eki; -ba/-be>-be (Kiyose 2000: 179-182) 
Cürçencede /i/ sesinden önce gelen diş ünsüzleri de Mançuçada değişime uğramıştır. Bu yüzden Cürçence çıkma hâli eki -ti ve dondi- "duymak" fiili Mançucada -ci ve donji- biçimlerinde görülür (Miyake 2017: 479).

Ming dönemi Cürçencesinin ses bilgisi bakımından Mançucaya oldukça yakın olduğu söylenebilir.

Şekil bilgisi ve söz dizimi bakımından Cürçence ve Mançuca arasında büyük bir fark olduğu söylenemez. Ancak, Cürçencedeki bazı eklerin işlevleri hâlâ tam olarak anlaşılamamıştır (Rachewilts ve Rybatzki 2010:268).

Cürçencede ilgi hâli eki - $i$, vasıta hâli eki de - gi biçimindedir. Ancak Mançucada bu eklerin aynılaştığı ve iki işlev içinde - $i$ ekinin kullanıldığı görülür (Miyake 2017: 480)

Temel kelime kadrosu bakımından da iki dil arasında düzenli ses değişiklikleri dışında önemli bir fark yoktur; Cürçence šeun "güneş" > Mançuca šun (Miyake 2017: 480). Ayrıca Cürçenceye Kitan dilinden alıntılanan birçok unsurun Mançucada da kullanıldığ1 görülür (Janhunen 2013: 52-57).

Cürçence ve Mançuca bazı araştırmacılar tarafından aynı dilin birbirinin devamı olan kolları olarak değerlendirilirken, bu ikisinin aslında farklı diller olduğu da ifade edilmektedir. Poppe, Cürçencenin Mançucaya çok yakın olduğunu, bu bakımdan bu dilin eski Mançuca olarak kabul edilebileceğini veya eski Mançucayla beraber aynı dilin farklı diyalektleri olarak değerlendirilebileceğini belirtir (1965: 28).

Kiyose, Cürçence ve Mançucanın tarihsel süreçte birbirinin devamı olmadığına gerekçe olarak iki dilin şu özelliklerini gösterir;

Cürçencede, proto-Tunguzca /u/ ve /ü/ sesleri /u/ sesinde birleşmiştir. Bu bakımdan Cürçencede ünlü uyumu kısmen bozulmuştur. Mançucada ise art damak ve ön damak ünsüzlerinden sonra bu iki ses ayırt edilebilir.

On birden yirmiye kadar olan sayılar iki dilde farklıdır;

\begin{tabular}{|c|c|}
\hline Cürçence & Mançuca \\
\hline amşo & juwan ети "on bir" \\
\hline jirqon & juwan juwe "on iki" \\
\hline yorzon & juwan ilan "on üç" \\
\hline durzon & juwan duin "on dört" \\
\hline toboxon & tofohon "on beş" \\
\hline nilxun & juwan niggun "on altı" \\
\hline darzon & juwan nadan "on yedi" \\
\hline niyuxun & juwan jakūn "on sekiz" \\
\hline 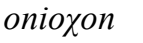 & juwan иуun "on dokuz" \\
\hline
\end{tabular}

Mançucada, yansıma sesler hariç, kelime sonunda bulunabilen tek ünsüz /n/ sesidir. Cürçencede ise /r/ sesi son ses konumunda bulunabilir;

$\begin{array}{ll}\text { Cürçence } & \text { Mançuca } \\ \text { mudur } & \text { muduri "ejderha" } \\ \text { xutur } & \text { hüturi "kut" } \\ \text { gemur } & \text { gemuri "hepsi, tamami" } \\ \text { mar "ihmal" } & \text { mara- "ihmal etmek" }\end{array}$


Ayrıca, aşağıda verilen ses değişimleri de, araştırmacıya göre Cürçenceden Mançucaya art zamanlı değişimler olarak değerlendirilemez;

$\begin{array}{ll}\text { Cürçence } & \text { Mançuca } \\ \text { jaçili } & \text { çaçari "çadır" } \\ \text { niyarma } & \text { niyalma "kişi" } \\ \text { ukçin } & \text { uksin "zırh" } \\ \text { nuşin } & \text { nusin "barış" } \\ \text { meterin } & \text { mederi "deniz" (Kiyose 2000: 184-185) }\end{array}$

$\mathrm{Bu}$ farklara rağmen Cürçence, Mançuca ve Sibecenin aynı dilin tarihi süreçteki kolları olduğu bu alandaki önemli bazı araştırmacılar tarafından kabul edilmektedir (Kiyose 1998: 123).

Cürçencenin yukarıda ana hatlarıyla verilen dilbilgisi özellikleri bakımından Mançucayla büyük oranda ortaklık göstermesinden dolayı, bugün elde bulunan Mançuca dilbilgisi çalışmalarını ihtiyatlı bir şekilde Cürçenceyi anlamak için de kullanmak mümkündür.

\section{Cürçencede Türkçe Kökenli Kelimeler}

Tunguz dillerinde erken dönemde görülen Türkçe kelimelerin bu dillere Moğolca aracılığıyla geçtiği araştırmacılar tarafından ifade edilir. Bunun sebebi, bu iki dilin erken dönemlerde doğrudan temas hâlinde olmamasıdır. Doerfer, Tunguzcada görülen Türkçe kelimelerin Moğolca aracılığıyla alıntılandığını şu şekilde gösterir;

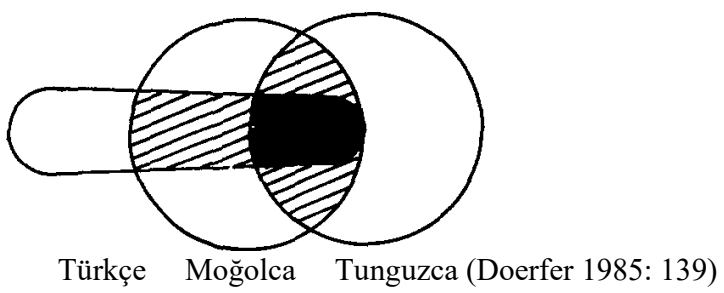

Buna göre, sadece Türkçe ve Tunguzca için, Moğolcayı dışarda bırakacak şekilde, bir kesişim alanı ön görülmez. Türk ve Tunguz dillerinin doğrudan birbirlerine temas etmeleri sonraki süreçlerde ve sadece belirli Türk (Yakut, Dolgan) ve Tunguz (Even, Evenki) dili için gerçekleşmiş̧ir (Janhunen 2013: 32). Jankowski eski Türkçe dönemi öncesinde Türkçenin temas ettiği dilleri Samoyed, İran dilleri, Moğolca, Toharca ve Çince olarak verir. Tunguz dillerini bu dönem için Türkçe ile temas eden diller arasında göstermez (Jankowski 2013: 537). Dolayısıyla, Cürçencede görülen Türkçe kelimelerin bu dile Moğolca ya da para-Moğolca dillerden alıntılandığı ifade edilebilir ${ }^{3}$.

\footnotetext{
${ }^{3}$ Mançucada görülen Türkçe kelimeler de bu dile Moğolca aracılığıyla girmiştir. Konuyla ilgili son yapılan çalışma için bk. Özalan 2021
} 
Cürçencede tespit edilen Türkçe kökenli kelimeler şunlardır ${ }^{4}$;

a-či-rh mu-lin †ajir morin "aygır at", Man. ajirgan ajirhan "aygır" (Nor. 11); Evk. ažirga, Sol. adigga adirga, Nan. ažirga "aygır” (SSTM I 17); Mo. azirg-a(n) "aygır" (Les. 62) ᄂTü adgır (MT 75, TMEN II 185-187)

an-č'un †ançun "altın"; Man. aisin, Neg. ajsin, Orç. aisi(n), Udg. aisi, Ulç. aisi(n), Ork. ajsi(n), Nan. ajsi (SSTM I 22-23); Mo. alta(n) (Les. 33) «Tü altın (MT 64, TMEN I 142-143, Khabtagaeva 2019: 32)

dol-lo-wen †doron "resmî mühür", Man. doro "töre, öğreti, yöntem, yol, ritüel, armağan" (Nor. 63); Orç. doro(n), Ulç. doro(n), Ork., doro(n), Nan. dorõ (SSTM I 216-217). Mo. törü "yasa, güç, düzen, nizam, kural, idare” (Les. 835) ŁTü. törü (TMEN I 264-267)

hūh-t'̄̄h-rh †hutur "kut", Man. hūturi "kut" (Nor. 141), Evk. kutu (SSTM I 440); Mo. kutug (Les. 992) ŁTü. kut (MT 136, TMEN III 551-554)

huh-tih-lah †hudila "kuskun", Man. küdargan "kuskun" (Nor. 182); Evk. kudurga (SSTM I 421); Mo. kudurgan (Les. 980) ŁTü. kudurgun (MT 100, TMEN III 477478)

huo-ni †honi "koyun", Man. honin "koyun" (Nor. 135); Evk. konin, Sol. xoni, Udg. xuani, Ulç. xoni(n), Ork. xoni(n), Nan. xonĩ (SSTM I 409-410); Mo. koni(n) (Les. 963) $\leftarrow$ Tü. qoń (MT 37, TMEN I 442)

hūh-čao-kih †huçaugi (Grube 1896: 93, SSTM II 924) “ün, şöhret”; paraMoğolca? ${ }^{5} \leftarrow$ Tü. kü çav (Pevnov 1997: 266)

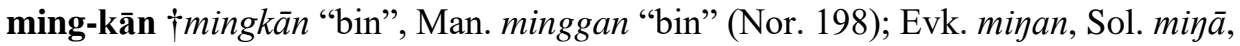
Neg. mingan, minga(n), Udg. minga(n), Orç. minga(n), Nan. minga $\bar{a}$, (SSTM I 537);

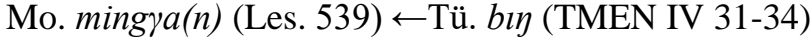

oh-hen †eihen "eşek", Man. eihen "eşek" (Nor. 71); Sol. eljig, Neg. eyxe, Ulç. eyxe, Nan. eyxe, (SSTM II 447); Mo. eljige(n) (Les. 311.) ŁTü eşgek (Rozycki 1994: 67)

oh-lu-t'eh †erte "erken", Man. erde "erken, sabahın ilk saatleri” (Nor. 76) Evk. erde, Sol. egd edde erde, Evn. erde, Nan. erde (STTM II 463); Mo. erte(n) (Les. 331) «Tü. erte (MT 76)

pih-t'eh-hei †bit[h]e'e "belge", Man. bithe "mektup, kitap" (Nor. 31); Evk. bit'ik, biçik, Sol. bitig, biteg, Neg. bitexe, Orç. bitige, bitxe, Ulç. bitxe, Ork. biçixe, Nan. biçxe, (SSTM I 86); Mo. biçig (Les. 101) ŁTü. bitig (MT 76)

\footnotetext{
${ }^{4}$ Çalışmada Cürçence kelimelerin önce Cincius'un karşılaştırmalı Tunguz-Mançu dilleri sözlüğünde verdiği transliterasyonlu biçimleri gösterilmiş, arkasından bunların Rozycki 1994'e göre muhtemel okunuşları $†$ işaretiyle verilmiştir. Cürçence kelimelere dair yapılacak yeni okuma tekliflerine bağlı olarak burada verilen listeye başka kelimelerin eklenmesi mümkündür.

${ }^{5}$ Tunguz dilleri içinde sadece Cürçencede görülmesinden dolayı kelimenin bu dile para-Moğolca bir dil üzerinden alındığı düşünülebilir. Ancak, Kane 2009, Janhunen 2013 ve 2015'te bu kelime tanıklanmamıştır. Bunula birlikte, Janhunen Kitan diline ait belgelerde tanıklanmayan bazı paraMoğolca unsurların Cürçence ve Mançucada korunduğunu belirtmektedir (2015: 584).
} 
poh-yang †bayan "zengin”, Man. bayan "varlıklı" (Nor. 26); Evk. bayan, Neg. bayan, Orç. baya(n), Udg. baya(n), Ulç. baya(n), Ork. baya(n), Nan. baya (SSTM, s. 65); Sib. bayin (Zikmundova, 2013: 206); Mo. bayan (Les. 76) ŁTü. bay (MT 37, TMEN II 259-260)

puh-su †bosu "bez", Man. boso "bez, kumaş" (Nor. 35); Neg. boso, Orç. busu,

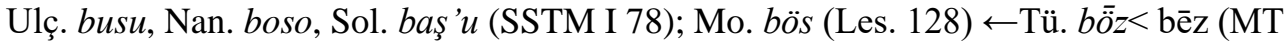
115)

t'eh-'oh †temge "deve", Man. temen "deve" (Nor. 276); Evk. temegēn, dial. tobo, Orç. teme, Nan. teme, Sol. temegē, (SSTM II 235), Mo. temege(n) (Les. 800) ŁTü. tebe (MT 77-78, TMEN II 669-671)

t'u-man †tuman "on bin", Man. tumen "tümen, on bin" (Nor. 284); Evk. tuman, Sol. tumũ, Orç. tume, Neg. tume, Udg. tume, Ulç. tume(n), Nan. tumē, (SSTM II 212213); Mo. tüme(n) (Les. 853) ŁTü. tümen (MT 78)

t’üh-lah †tura "direk", Man. tura “direk, sütun, çadır direği”; Evk. turu, Sol. törö, Neg. toyo, Orç. tū, Ulç. tura, turu, Ork. toro, torro, turu, Nan. tora (SSTM II 221); Mo. tura "kale, şehir, kasaba" (Les. 843) ŁTü. tura "arkasına saklanılan şey, kalkan; kale, tahkim edilmiş yer; şehir, kasaba (EDPT 531), (MT 38, Khabtagaeva 2019: 118)

\section{Sonuç}

Tunguz dilleri tarihi bakımından oldukça önemli bir konumda olan Cürçence gösterdiği şekil ve ses bilgisi özelliklerinden dolayı Tunguz dilleri içinde ayrı bir konumda değerlendirilir. Birçok niteliklerinin benzer olmasından dolayı Cürçen, Mançu ve Sibe dilleri aynı dilin tarihsel kolları olarak ele alınır. Cin ve Ming dönemlerinde yazılı kaynaklarla takip edilebilen Cürçenceye Moğol dilleri aracılığıyla bazı Türkçe kelimeler girmiştir. Türkçe kökenli bu kelimelere bakılınca bunların temel kelimeler olmaktan çok belirli kültür alanlarına (hayvan yetiştiriciliği, devlet yönetimi gibi) ait kelimeler olduğu görülür. Sinitik yazı sistemleriyle kaydedilen Kitan veya Tangut dillerinde olduğu gibi, Cürçence metinlerin de bu dilin fonolojik yapısını kesin bir biçimde yansıttığ s söylenemez (Burykin 1999: 30). Bu nedenle Cürçencedeki Türkçe kökenli unsurların fonolojik yapısına bakarak bunların tarihî süreçleriyle ilgili sonuç çıkarmak kolay değildir. Bunlardan huh-tih-lah †hudila "kuskun" kelimesinin Cürçenceden Mançucaya aktarılmadığını söyleyebiliriz. Mançucadaki kūdargan şekli daha sonraki bir dönemde Moğolcadan alıntılanmış olmalıdır. Erken dönem Moğolcadan Mançucaya alıntılarda /rg/ ünsüz grubu /c/ olarak gelişmiş, geç dönem alıntılarında ise korunmuştur (Rozycki 1994: 227-228). Mançuca kelimede /rg/ ses grubunun korunması, küdargan kelimesinin Mançucaya Cürçenceden intikal etmediğini, daha sonra Moğolcadan alındığını gösterir. Ayrıca, Cürçencedeki Türkçe kökenli kelimelerin Tunguz dillerindeki yayılım oranı da bu kelimelerin çok erken dönemlerde alındığını ortaya koyan başka bir göstergedir. thuçaugi "ün, şöhret" < kü çav Tunguz dilleri içinde sadece Cürçencede görülen Türkçe kökenli bir kelimedir. Kelimenin sadece Cürçencede görülmesi bunun para-Moğolca bir dil üzerinden Cürçenceye alınmış olması ihtimalini akla getirmektedir. 


\section{Dil Adı Kısaltmaları}

\begin{tabular}{|c|c|c|c|c|c|c|}
\hline Cür. & : Cürçen & Mo. & Moğol & Ork. & : Orok & Udg. \\
\hline Evk. & : Evenki & Nan. & Nanay & Sib. & : Sibe & Ulç. \\
\hline Evn. & Even & Neg. & Negidal & Sol. & : Solon & \\
\hline Man. & : Mançu & Orç. & Oroç & Tü. & : Türk & \\
\hline
\end{tabular}

\section{Kısaltmalar ve Kaynakça}

Alonso de la Fuente, José Andrés (2011) Tense, Voice and Aktionsart in Tungusic: Another Case of «Analysis to Synthesis»? Tunguso-Sibirica 32. Wiesbaden: Harrassowitz.

BENZING, Johannes (1956). Die tungusischen Sprachen: Versuch einer vergleichenden Grammatik. Wiesbaden: Steiner.

BuRYKin, Alexey Alexeyevich (1999). "Morphological aspects of the language of the Jurchen script". Writing in the altaic World. (Edt. Juha Janhunen-Volker Rybatzki). Helsinki: Finish Oriental Society, 29-39.

Cincius, V. I. (1949). Sravnitel'naâ fonetika tunguso-man'čžurskih jazykov. Leningrad: Učpedgiz; Leningradskoe otd.

DOERFER, Gerard (1978). "Classification problems of Tungus". Beiträge zur nordasiatischen Kulturgeschichte. (Edt. M Weiers), Wiesbaden: Otto Harrassowitz, 1-26.

DOERFER, Gerard (1985). "The Mongol Tungus-Connections". Language Research, 21: 135-144.

EDPT $=$ ClAuSON, Sir Gerard. (1972). An etymological dictionary of pre-thirteenth-century Turkish. Oxford: Oxford University Press.

GRUBE, Wilhelm (1896). Die Sprache und Schrift der Jučen. Leipzig: Harrassowitz.

Huang, Pei (1990). "New Light on The Origins of The Manchus". Harvard Journal of Asiatic Studies, 50: 239-282.

İKeGAMI, Jiro (1974). "Versuch einer Klassifikation der Tungusischen Sprachen". Sprache, Geschichte und Kultur der Altaischen Volker, (Edt. G. Hazai), Berlin:Akademie Verlag, 271-272.

JANHUNEN, Juha (1994) "On the formation of Sinitic Scripts in Medieval Nothern China". Journal de la Sociéte Finno-Ougrienne, 85: 107-124.

JANHUnEN, Juha (1996). Manchuria: an Ethnic History. Helsinki: Finno-Ugrian Society.

JANHUnEN, Juha (2004). "From Choson to Jucher: On the Possibilities of Ethnonymic Continuity in Greater Manchuria". Studia Etymologica Cracoviensia, 9: 67-76.

JANHUNEN, Juha (2012). "The expansion of Tungusic as an ethnic and linguistic process". Recent Advances in Tungusic Linguistics. Turcologica 89 (Edt. A. L. Malchukov-L. J. Whaley), Wiesbaden: Harrassowitz, 5-16.

JANHUnEN, Juha (2013). "On Para-Mongolic vs. Pre-Proto-Mongolic loanwords in JurchenManchu. Mongolic languages", History and present: Extended abstracts for the Conference St. Petersburg, Kasım 21-23, Rossijskaia Akademija Nauk, Institut Lingvisticheskikh Issledovanij, 52-57.

JANHUNEN, Juha (2015). "Observations on the Para-Mongolic elements in Jurchenic". Acta Linguistica Petropolitana, 11(3): 575-592.

JANKOWSKI, Henryk (2013). "Altaic Languages and Historical Contact", Current Trends in Altaic Linguistics: A Festschrift for Professor Emeritus Seong Baeg-in on his 80th Birthday. (Edt. J. Kim - D. Ko). Seoul: Altaic Society of Korea, 523-545.

KANE, Daniel (1989). The Sino-Jurchen Vocabulary of the Bureau of Interpreters. Bloomington: Indiana University.

KANE, Daniel (2009). The Kitan Language and Script. Leiden: Brill.

Khabtagaeva, Bayarma. (2019). Language Contact in Siberia: Turkic, Mongolic, and Tungusic Loanwords in Yeniseian. Boston: Brill.

KiYOSE, Gisaburō Norikura (1977). A Study of the Jurchen Language and Script: Reconstruction and Decipherment. Kyoto: Hōritsubunka-sha.

KiYose, Gisaburō Norikura (1998). "Dialectal Lineage from Jurchen to Manchu". Central Asiatic Journal, 42: 123-127. 
KiYose, Gisaburō Norikura (2000). "Genealogical Relationship of Jurchen Dialects and Literary Manchu”. Central Asiatic Journal, 44: 177-189.

MENGES, Karl H. (1968). Die tungusischen Sprachen. Leiden: Brill.

MiYAKE, Marc (2017). "Jurchen language". Encyclopedia of Chinese language and linguistics. (Edt. Rint Sybesma ), Leiden: Brill. 478-480.

MT = DOERFER, Gerard (1985). Mongolo-Tungusica. Weisbaden: Harrassowitz.

Nor $=$ NoRman, Jerry (1978). A concise Manchu-English lexicon. Seattle, University of Washington Press.

ÖZALAN, Uluhan (2021). "Mançucada Türkçe Kökenli Kelimeler". IX. Uluslararası Türk Dili Kurultayl. 26-30 Eylül 2021. Ankara-Türkiye.

Pevnov, Alexandr M. (1997). Chzhurchzhen'skij yazyk". Yazyki míra. Mongol'skie yazyki, tungusoman'chzhurskie yazyki, yaponskij yazyk, koreiskij yazyk. (Edt. Vladimir A. Alpatov), Moskova: Indrik. 260-267.

PoPPE, Nikolaj Nikolaevič (1965). Introduction to Altaic Linguistics. Wiesbaden: Harrassowitz.

Rachewiltz, I. de; RyBAtzKI, V. (2010). Introduction to Altaic Philology: Turkic, Mongolian, Manchu . Leiden: Brill.

ROZYCKI, William (1994). Mongol Elements in Manchu. Bloomington: Indiana University, Research Institute for Inner Asian Studies.

SSTM = Cincius, V. I. (1975, 1977). Sravnitel'njy slovar' tunguso-man'čžurskix jazykov 1-2. Leningrad: Nauka.

TMEN = DOERFER, Gerard. (1963-1975). Türkische und mongolische Elemente im Neupersischen 14. Wiesbaden: F. Steiner.

Vovin, Alexander (2006). "Why Manchu and Jurchen look so non-Tungusic". Tumen jalafun Jecen akū: Manchu Studies in Honor of Giovanny Stary, (Edt. A. Pozzi-J.A. Janhunen-M. Weiers), Tunguso-Sibirica 20, Wiesbaden: Harrassowitz, 255-266.

Zikmundova, Veronika (2013). Spoken Sibe: Morphology of the Inflected Parts of Speech. Prague: Karolinum Press. 